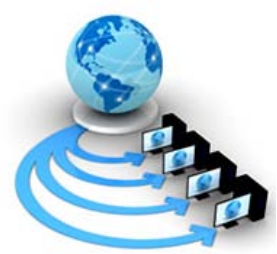

Volume 8, No. 7, July - August 2017

ISSN No. 0976-5697

International Journal of Advanced Research in Computer Science

RESEARCH PAPER

\author{
Available Online at www.ijarcs.info
}

\title{
A NOVEL WEIGHT BASED CLUSTERING ROUTING PROTOCOL SCHEME FOR IMPROVED QOS(QUALITY OF SERVICE) IN ADHOC NETWORK
}

\author{
Prabhdeep Kaur \\ Department of Computer Science \& Engg \\ Sri Sai College of Engg and Technology, Manawala \\ (Amritsar) Punjab (India)
}

\author{
Rimmy Chuchra \\ Department of Computer Science \& Engg \\ Sri Sai College of Engg and Technology, Manawala \\ (Amritsar) Punjab (India)
}

\begin{abstract}
Wireless Networks are more preferred now a days because of these are independent of their geographical area. The development of such type of networks is proper utilization of resources that leads to imaginative and proficient results in networking field. In this paper, authors uses adhoc network for wireless communication between different mobile nodes. Each mobile node is connected with wireless links. This research paper is working in two sections.In section 1,Authors applies location based clustering for making clusters. And in section 2, a cluster based routing protocol (CBRP) is modified with designing a new scheme.The minimum cluster id is to be preferred in current modified cluster based routing protocol (MCBRP) approach.The main motive to design this paper is to improve quality of service of adhoc networks by analyzing four different- 2 parameters \& metrices.The metricsconsideration taken by author's viz. throughput, packet delivery ratio(PDR), and average delay and packet loss is an important factor.
\end{abstract}

Keywords: wireless communication, Adhoc Network, Clustering based routing protocol, Clustering, quality of service, average delay, throughput, packet delivery ratio and packet loss.

\section{INTRODUCTION}

The term "wireless" referred to tele-communication. Communication between two or more device can be within the short range or may be thousands of kilometers range. Wireless Networks term is refers to a kind of networking that does not require cables to connect with devices during communication. The more popularity of such type of network [5] is it basically covers a large area. Such type of network uses radio signal frequency to communicate among computers and other network devices. Two types of communication are possible through wireless networks that are either in direct manner or in indirect manner. Radio waves are used for transmission at physical level. It is widely known as Wi-Fi

or WLAN. With the help of this network, devices can be joined easily with the help of radio frequency without wires to sharing information [6].The wireless adhoc network [4] [10] is diagrammatically represented as in figure number 1 which is given below:-

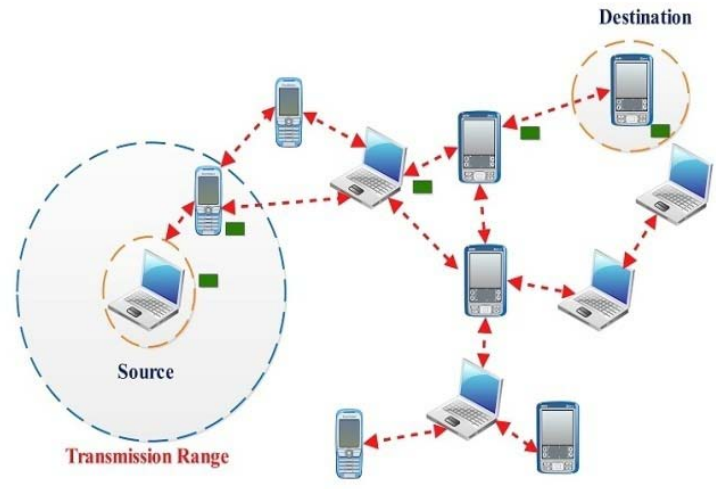

Figure 1: Diagram of Wireless Ad-hoc Network [1].
And the other main features of wireless Adhoc network are:$\checkmark$ Infrastructure-less:MANET [8] [9] does no longer depend on any centralized infrastructure. All communications between the nodes are provided via wireless connectivity. Every node acts as an independent router and generates independent information. Ad-hoc networks are also an infrastructure networks. The conversation between the nodes is viable most effective through radio signals.

$\checkmark \quad$ Dynamic Topology: Nodes are freely to transport therefore the community topology may also exchange randomly and rapidly at unpredictable times and might consist of both unidirectional and bidirectional links.

$\checkmark \quad$ Self-Configuring: MANET [8] [9] has decentralized infrastructure, with all mobile nodes functioning as router and all Wi-Fi devices being interconnected to one another. MANET [8] [9] is a selfconfiguring network in which network activities inclusive of the discovery of the topology and transport of messages are completed via the nodes themselves.

$\checkmark \quad$ Node Movement: Mobile nodes are autonomous units in network which continuously change their position and topology independently. So due to continuously motion of nodes, the topology changes frequently which means tracking down of node become difficult. The routing information of node changes continuously as their movement becomes random.

$\checkmark \quad$ Scalability: due to mobility of nodes, scale of adhoc community changing all the time. So scalability is a major trouble regarding safety. Security mechanism must be capable of handling a big community as well as small ones.

$\checkmark \quad$ Limited Power Supply: The nodes in mobile adhoc network need to consider restricted power supply, which will cause several problems. A node in mobile ad-hoc 
network may behave in a selfish manner when it is finding that there is only limited power supply.

$\checkmark \quad$ Energy Constrained Operation: Some or all MANET[8] [9] nodes relay on batteries so important challenges is to design the system to consume law battery power.[5]

$\checkmark \quad$ Adversary inside the Network: Adversary inside the network: The cellular nodes inside the MANET can freely be part of and leave the community. The nodes within network might also behave maliciously. This is hard to hit upon that the behavior of the node is malicious. Consequently this assault is more risky than the outside assault. These nodes are called compromised nodes.

$\checkmark \quad$ No Predefined Boundary: In portable particularly appointed systems, we cannot correctly symbolize a bodily restriction of the device. The nodes work in nomadic surroundings wherein they are allowed to enroll in and go away the wireless community. As soon as an adversary comes in the radio range of a node it will likely be capable of speak with that node.

$\checkmark \quad$ Resource Availability:Resource availability is a major issue in MANET [8] [9]. Providing secure communication in such changing environment as well as protection against specific threats and attacks, leads to development of various security schemes and architectures. Collaborative ad-hoc environments also allow implementation of self-organized security mechanism [2].

The increased growth of wireless adhoc network is its maximum use in real life applications as an example military battlefield, commercial sector and especially in personnel area network (PAN) [2]. These real life applications can be run on separate types of routing protocols used in MANETS that can be diagrammatically represented as in figure number 2 :

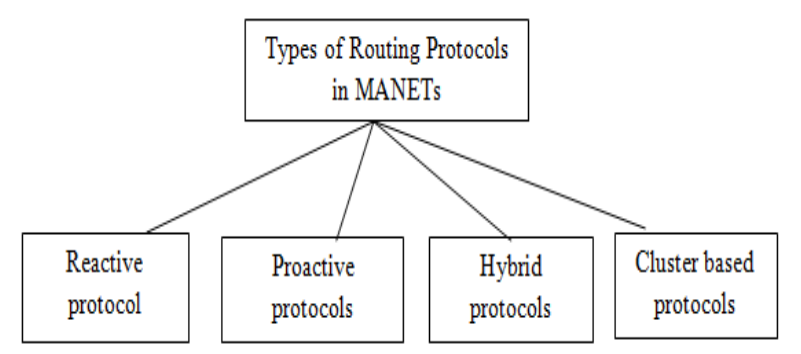

Figure 2: Classification of Routing Protocols in MANETs [3].

In This research paper is working in two sections. In section 1, Authors applies location based clustering for making clusters. And in section 2, a cluster based routing protocol (CBRP) [7] is modified with designing a new scheme. The minimum cluster id is to be preferred in current modified cluster based routing protocol (MCBRP) approach. The main motive to design this paper is to improve quality of service of adhoc networks by analyzing four different-2 parameters \& metrices. The metrics consideration taken by author's viz. throughput, packet delivery ratio (PDR), and average delay and packet loss is an important factor. Each factor can be described below one by one:

$\checkmark \quad$ Throughput: The particular throughput is the ratio regarding complete number of data which often grows to the particular device in the sender on the time period.
Throughput can be calculated by following formula as given below:-

Throughput $=$ Packet size $*$ No of received packet* 8/ (Stop time-Start time).

Where Stop time= last packet receiving time.

Start time $=$ first packet transmitting time.

$\checkmark \quad$ Average Delay of Data Packets: Delay indicates the time it got for just a supply going in the origin from the source to the destination. The Delay is an average time period so that you can traverse the particular supply inside community. This can be calculated by using following formula as given below:-

Delay $=$ (time packet received- time packet sent) $/$ total number of packet received

Packet Delivery Ratio: This is a ratio regarding complete supply received on the complete supply delivered to the particular community.

$\mathrm{PDR}=\sum$ Number of packets received $/ \sum$ Number of packets sends.

II Research Design

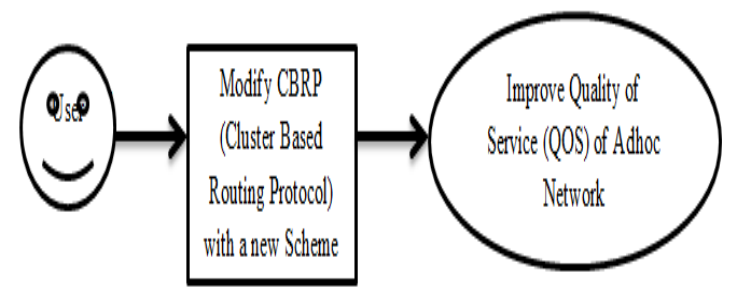

Figure 3: Interaction between User and Adhoc Network.

\section{PROPOSED METHODOLOGY}

FLOWCHART (MCBRP) 


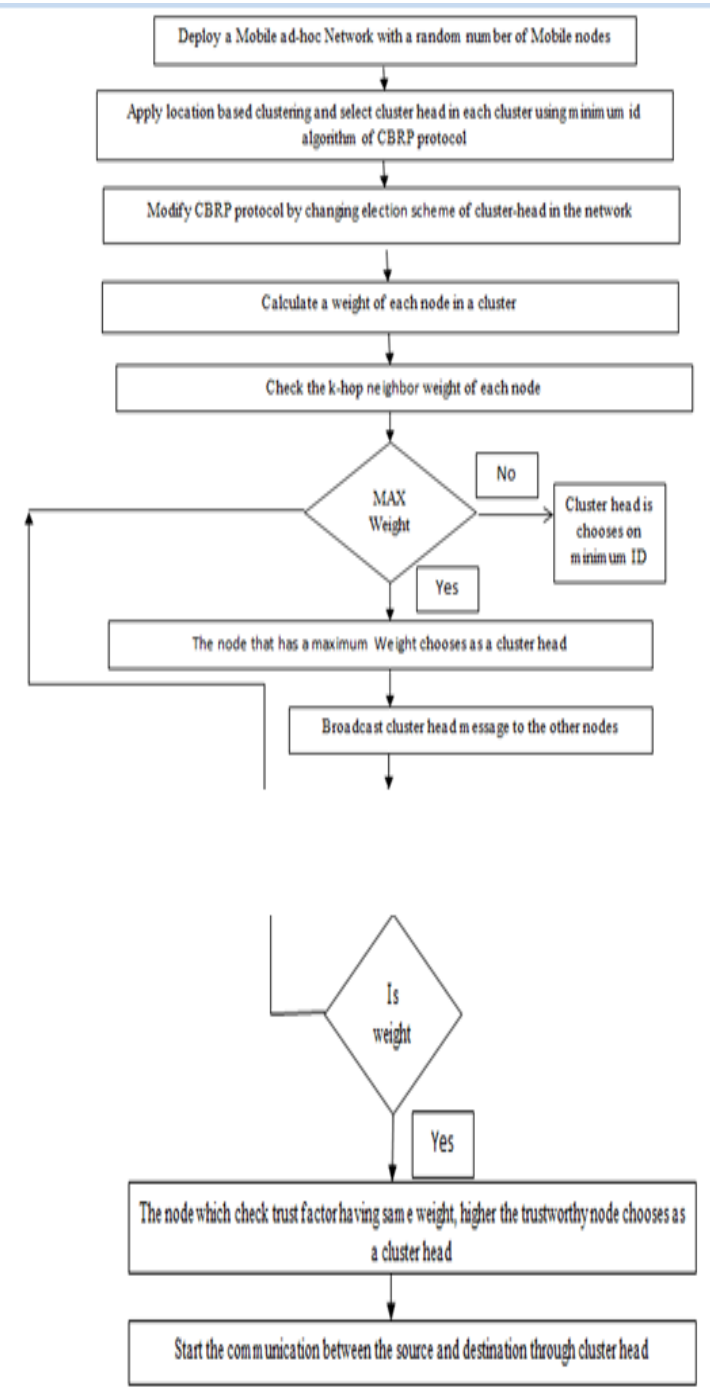

Figure 4: A new Scheme implemented in CBRP (Cluster Based Routing Protocol).

\section{CONCLUSION}

Different types of Adhoc network protocols are discussed in this paper. This significance to study adhoc network is to improve its quality of service (QOS) when mobile nodes are communicating in wireless network. Authors designed a new scheme for improving the quality of service while applying changes in Cluster Based Routing Protocol
(CBRP) and termed as modified cluster based routing protocol (MCBRP). The minimum cluster id is to be considered in this current approach. There are 4 major metrices are considered in this research paper viz. throughput, packet delivery ratio, packet loss and average delay. Each one is considered as an important factor for analyzing the performance of the adhoc network.

\section{REFERENCES}

[1] Z.Theodore, C.L.Helen, T.Panagiotis, V.Stamatis "Trust Management in Wireless Sensor Networks", European Transactions on Telecommunications, 2010.

[2] C. Naveen et al. "A Distributed weighted cluster based routing protocol for MANETs”, Springer- Verlag Berlin Heidelberg, pp 147-151, 2011.

[3] S.K.Dhirendra et al. "An efficient cluster based routing protocol for MANET”, 3rd IEEE International Advance Computing Conference (IACC), pp: 224-229, 2012.

[4] Manpreet Kaur and Sarabjeet Kaur et al. "An optimized Weight Based Clustering routing Protocol Scheme in MANET for improving its quality of service”,Int Journal of Engineering Applied Sciences and Technology,pp: 7078,2016.

[5] C. Mahima, M. W. Ahmad, "Review on MANET: Characteristics, Challenges, Imperatives and Routing Protocols”,International Journal of Computer Science and Mobile Computing, Vol. 3, No. 2, pp: 432-437, 2014.

[6] K. G. Anuj, S. Harsh, and K. V. Anil, "Review of Various Routing Protocols for MANETs", International Journal of Information and Electronics Engineering, Vol. 1, No. 3, pp: 251-259, 2011.

[7] R. Balasubramaniyan, M. Chandrasekaran, "An Improved Cluster Based Routing Protocol with Backup Cluster head for MANETs", ARPN Journal of Engineering and Applied Sciences, Vol. 10, pp: 4927-4930, 2015.

[8] R. Rajesh, Dr A. Saradha, "Efficient MAC Based AODV Routing Protocol to improve the efficiency of MANET", Journal of Computer Science and Engineering, Vol. 2 No. 6, pp: 37-48, 2015.

[9] S. Rajesh, S. S. Barde, "Survey on Cluster Based Routing Protocol in MANETs", International Journal of Science and Research, Vol. 4, No. 1, 2015.

[10] B. U. Rajesh, K. Rakhi Purnima, “A Comparative Study of Topology and Position Based Routing Protocols in Mobile Ad Hoc Networks”, International Journal of Advanced Research in Computer Science \& Technology, Vol. 2, No. 2, pp: 72-75, 2014. 